Article

\title{
Shifting Approaches to Planning Theory: Global North and South
}

\author{
Vanessa Watson \\ School of Architecture, Planning and Geomatics, University of Cape Town, 7701 Rondebosch, South Africa; \\ E-Mail: vanessa.watson@uct.ac.za
}

Submitted: 23 August 2016 | Accepted: 29 November 2016 | Published: 6 December 2016

\begin{abstract}
Planning theory has shifted over time in response to changes in broader social and philosophical theory as well as changes in the material world. Postmodernism and poststructuralism dislodged modernist, rational and technical approaches to planning. Consensualist decision-making theories of the 1980s took forms of communicative and collaborative planning drawing on Habermasian concepts of power and society. These positions, along with refinements and critiques within the field, have been hegemonic in planning theory ever since. They are, in most cases, presented at a high level of abstraction, make little reference to the political and social contexts in which they are based, and hold an unspoken assumption that they are of universal value, i.e. valid everywhere. Not only does this suggest important research methodology errors but it also renders these theories of little use in those parts of the world which are contextually very different from theory origin-in most cases, the global North. A more recent 'southern turn' across a range of social science disciplines, and in planning theory, suggests the possibility of a foundational shift toward theories which acknowledge their situatedness in time and place, and which recognize that extensive global difference in cities and regions renders universalized theorising and narrow conceptual models (especially in planning theory, given its relevance for practice) as invalid. New southern theorising in planning is drawing on a range of ideas on societal conflict, informality, identity and ethnicity. Postcolonialism and coloniality have provided a useful frame for situating places historically and geographically in relation to the rest of the world. However, the newness of these explorations still warrants the labelling of this shift as a 'southern theorizing project' in planning rather than a suggestion that southern planning theory has emerged.
\end{abstract}

\section{Keywords}

collaborative and communicative planning; global South; southern planning theory; universalized theory

\section{Issue}

This article is part of the issue "Paradigm Shifts in Urban Planning", edited by Matthias Drilling (University of Applied Sciences and Arts Northwestern Switzerland, Switzerland), Efrat Eizenberg (Israel Institute of Technology, Israel), Janet Stanley (University of Melbourne, Australia), Lee Boon Thong (Nilai University, Malaysia) and Andreas Wesener (Lincoln University Canterbury, New Zealand).

(C) 2016 by the author; licensee Cogitatio (Lisbon, Portugal). This article is licensed under a Creative Commons Attribution 4.0 International License (CC BY).

\section{Introduction}

Over the last several decades the field of planning theory has splintered into a large number of different and competing positions, many of which have more recently been challenged epistemologically by theorists taking a southern and postcolonial perspective. Broader philosophical shifts in cognate disciplines towards post structural and postmodern thinking undoubtedly broke the monopoly of the modernist, rational, technical planning model which held sway in the 1950s and 1960s. But plan- ning thought has also been influenced by changing social, political and material conditions across the globe: the shifting relationship between planning and markets; the declining dominance of the state in some parts of the world in managing change in the built environment; and new global issues such as sustainability and climate change, urban and regional inequalities, ethnic and identity claims and migration. The purpose of this article is to argue that a "foundational" (Allmendinger, 2002) shift is occurring in planning theory as new perspectives question some of the fundamental assumptions of 
previous planning ideas. These southern theorists take both global (relational) and local (recognizing the importance of context and place) views, and while it is far too early to suggest a coherent southern position, the article offers some examples of emergent thinking and their commonalities.

The first part of this article gives an overview of these multiple strands of contemporary 'mainstream' planning thought and traces their sources of influence which, in themselves, are often overlapping and interwoven. The second part of the article then argues that these positions have a common epistemological base which has been open to challenge from planning theorists questioning their validity and generalizability. Southern planning theorizing (a broad term covering distinct strands and regional variation) starts from different premises and different sets of assumptions, and different ambitions as to where and how such theory can be useful.

\section{The Splintering of Postmodern Planning Theory}

The rational, technical, planning model of the 1950s and 1960s had origins within a positivist epistemology, rooted in the enlightenment tradition of modernity, and was concerned primarily with procedural planning issues. In keeping with its intellectual informants, this model assumed that through "the application of scientific knowledge and reason to human affairs, it would be possible to build a better world, in which the sum of human happiness and welfare would be increased" (Healey, 1992, p. 145), and that this could be achieved by the application of a scientifically rational method by rational individuals (planners). This method took the form of a set of steps managed by the planner. Engagement with stakeholders and communities was not part of this process and the planners' role was that of the technical expert in managing the process.

The 1980s saw a philosophical break from the dominance of a modernist, positivist orientation in a number of social science disciplines, and a shift towards 'postpositivism' which Allmendinger (2002, p. 87) defines as:

- "a rejection of positivist understandings and methodologies (including naturalism) and embraces instead approaches that contextualize theories and disciplines in larger social and historical contexts;

- normative criteria for deciding between competing theories;

- the ubiquity of variance in explanations and theories; and

- an understanding of individuals as self-interpreting, autonomous subjects."

Postmodernism, post-structuralism and post-positivism in the social sciences found expression in a range of new social theories which planning theorists drew on to find new ways to explain and suggest roles for planning. All- mendinger (2002, p. 77) describes planning theory in the 1980 s as being in a "hyperactive state" giving rise to new theories such as neoliberal and public choice perspectives; postmodern planning; neo-pragmatism; political economy approaches and collaborative planning. In the years since Allmendinger's 2002 attempt to provide a typology of planning theory this hyperactivity and diversification has continued. There have been critiques and refinements of earlier post-positivist planning theories as well as further new planning ideas drawing on social science thinking on complexity, assemblages, actornetwork theory, power, feminism, ethnicity, race and identity politics, the post-political, new institutionalism, post-colonialism and issues such as rights, informality, resistance, environment and climate change, technology and more. Debates on planning ethics and values have also continued, cutting across many of these issues and ideas.

\subsection{Communicative and Collaborative Planning Theory}

In the early days of the post-positivist shift, communicative and collaborative planning had a clear dominance and critiques and refinements of these strands of theory, often drawing on other social science concepts, are still very evident in journal publications. In two topranked planning theory journals (Planning Theory and the Journal of Planning Education and Research) articles in this field still (August 2016) occupy four out of the top five 'most cited' listings. It is therefore worth elaborating on these areas of planning theory, strands within them, and their epistemological standpoint, before moving on to how different positionings of planning theory are emerging from a global and 'southern' theory perspective.

Communicative and collaborative planning ideas emerged as early post-positivist theoretical moves. Both served to shift attention away from finding 'objective laws' to govern social behaviour towards the sociallyconstructed ways in which social norms and practices are produced, legitimated, become hegemonic and are transformed. Both were inspired by Habermasian communicative theory but place and context, as well as locally dominant intellectual traditions, underlie the emergence of the two different but related sets of ideas.

In the United States, John Friedmann (1973) offered an early critique of the rational planning model and a recognition of the importance of interpersonal relations in effective planning. At about the same time Donald Schon $(1971,1983)$ also began to develop an interest in how professionals learn through doing, rather than drawing on abstract rules or theories. In developing this line of thought, John Forester (1989) used Habermas and critical pragmatist thinking (and its links on this continent to the ideas of Rorty) to draw attention to the way public professionals collaborate in practice. Innes (1995) developed ideas of how planners acquire knowledge in practice in consensus-building processes. Gen- 
erally these theorists argued for a focus on action and research rather than on abstract theory in the development of planning processes (Hoch, 1994). The term 'communicative planning', linked to these ideas, focuses on the social relations which connect actors together and the dynamics of these relations in planning practice.

In the UK, Patsy Healey drew, in part, on Giddens's structuration ideas and the European perspective of individuals embedded in constraining institutional and social relations (Healey, 1997a) to understand the work of planners and how institutions shaped plan-making. ${ }^{1}$ She adopted the term 'collaborative planning' with emphasis on the institutional context within which these processes take place. Norwegian planning theorist Tore Sager (1994), as well, used Habermasian ideas of communicative rationality, but was also influenced by critical pragmatism and Foucault's perspective on power.

Allmendinger's (2002, p. 93) noting of geographical difference is significant: he suggests that US-based thinkers were responding to the nature of planning in the US which was "more varied and fluid both institutionally and in terms of processes and ends", while British and European thinkers were responding to a context "where more uniform and concrete processes and institutions help structure outcomes and ends". However, changing the scalar lens through which to understand these positions highlights their commonalities. Planning theorists on both sides of the Atlantic were immersed in planning in advanced capitalist economies where the nature of cities and regions, their institutional capacities and management, and the functioning of civil society, were (and still are) very different from many other parts of the world. And, argues Allmendinger (2002, p. 93), they shared a similar world view, paradigm or "framing theory" in planning which he describes as "a reflexive modernist frame [which] points towards a realist ontology". Their realist position is at variance with mainstream postmodernism and also with those ideas which celebrate societal difference: communicative and collaborative planning processes acknowledge difference but then work towards a Habermasian idea of consensus. Further, theorists continue the interest of rational scientific planning in a focus on decision-making processes in planning rather than outcomes (Yiftachel, 1989). The work of the Fainsteins (2013) has been a significant exception here.

A central source of common thinking for collaborative and communicative planning lies in the work of Jurgen Habermas' communication theory and his understanding of how power operates in processes of dialogue (Harris, 2002; Purcell, 2009). With a concern to protect and extend democracy, Habermas conceptualizes the "life-world" (or public sphere) as separate from and outside "the system" of formal economy and government. Within the life-world it is possible for rational and inherently democratic human beings to reach consensus, and co-ordinate action, through the process of communication (communicative rationality). Here the "force of the better argument" will determine the final validity of a particular position. Habermas recognizes that communication can be distorted in various ways and puts forward a set of criteria, or discourse ethics, to guide communication processes: if processes are inclusive, empathetic, and open, and if existing power differences between participants can be neutralized, then the outcome of such a process can be considered valid (Habermas, 1990a, 1990b). For many communicative planning theorists, this has come to mean that the aim of planning is a just process, and that if the process is just, the outcome (for example, the achievement of socially just cities) will be as well (see Fainstein \& Fainstein, 2013).

Communicative and collaborative planning theorists (although in different ways) echo Habermas' faith in civil society as a source of democracy, and as a vehicle for placing pressure on the state to act more responsively. Healey refers to the "democratic deficit" (the distance between the state and civil society), and argues that planning "seeks ways of recovering a new participatory realization of democracy and of reconstituting a vigorous, inclusive public realm that can focus the activity of governance according to the concerns of civil society" (Healey, 1999, p. 119). The state, in terms of this position, is therefore downgraded as a role player relative to non-state actors, and civil society is seen as the main standard-bearer of the democratic project.

Habermas' assumption regarding the potentially consensual nature of discourse in the public sphere has also influenced communicative planning theorists (see Huxley, 2000), although to varying degrees. While writers in this school do not deny the operation of power, the hope still holds that if communication processes are correctly managed (according to Habermas' discourse ethics), then it is possible for voluntary but binding agreements to be reached. Basic to their position is an assumption of universal citizenship, where differences between actors occur mainly at the level of speech or ideas and can be overcome through argumentation. ${ }^{2}$ Thus: "the power of dominant discourses can be challenged at the level of dialogue; through the power of knowledgeable, reflective discourse; through good arguments; and through the transformations that come as people learn to understand and respect each other across their differences and conflicts" (Healey, 1999, p. 119). Healey refines the idea of universal citizenship further to acknowledge that communicating groups may operate within different "systems of meaning", which means that "we see things differently because words, phrases, expressions, objects, are interpreted differently according to our frame of reference" (Healey, 1992, p. 152). The assumption remains that these differences can be accommodated in a consensus-seeking process (Flyvbjerg, 1998; Purcell, 2009).

\footnotetext{
${ }_{1}$ Important early published sources of these ideas are Forester (1989) and Healey (1992, 1997b).

${ }^{2}$ Noting that John Forester has insisted that he did not hold with imaginary ideals of speech but rather with the power of planning in practice.
} 


\subsection{Critiques and Shifts}

The centrality of communicative and collaborative positions in planning theory over the last two and a half decades has inevitably given rise to numerous critiques, as well as refinement of the ideas by early proponents and others. The wide and ever-expanding field of postmodern social science theory has been a source of many of these ideas.

It is not possible here to do justice to this rich field of theorising and this section will focus on just one aspect which has inspired critique and which has also proved to be a source of ideas for southern thinkers. Habermas assumes that communicating groups are involved in dialogue on relatively equal terms, and power imbalances inherent in patriarchal, class-based (or ethnicity or race-based) societies, or in different or conflicting worldviews, will either not find their way into these processes, or can somehow be managed. This could be seen as a liberal conception of society within a prevailing western philosophy which assumes consensus as an unquestioned possibility. But, as mentioned above, this sits uneasily with those postmodern theories which recognize and celebrate social difference.

The "cultural turn" in social theory raised interest in how culture and context shapes knowledge and behaviour (Storper, 2001) and inspired an important strand of planning theory concerned with how planning can function where there are social divides and conflicts. New work widened the range of sources from which difference can emerge in planning: class or material circumstances, ethnicity, gender, age, race, religion, sexuality, world-view etc. The clear connection between cultural difference and place (or context) also introduced (possibly for the first time) a recognition that universalized (or place-blind) planning theory had its limitations. Watson (2002), for example, argued that governance, the nature of civil society, and relationships to land and place are very different in the African context. The work of Fincher and Jacobs (1998) in urban theory was important here. Bringing together cultural, political and economic positions on difference, together with a perspective on place and location, they produced a "located politics of difference" (Watson, 2006). Fincher and Jacobs (1998) describe the major shift in thinking about difference which is away from something that is pre-given and fixed to something that is socially produced and multiply located. What this points to, they argue, is the multiplicity of differences that may cohere around any one person: "social distinctions are constituted in specific contexts through multiple and interpenetrating axes of difference...and at any one time we may be fixed into or strategically mobilize different aspects of the array of differences through which our embodied selves are known" (p. 9). Which aspect dominates is not haphazard: often the attribute to be emphasized is that which contributes most significantly to a subject's marginalization or empowerment and this can and does vary significantly with place, and time.
However, new planning ideas on difference usually broke with the concept of universal citizenship without necessarily recognizing place-based difference. Leonie Sandercock's work (1998) on multiculturalism questioned what constituted citizenship, how this is fragmented by identity, and the role of the planner in relation to this question. As opposed to the idea of universal citizenship, her society is structured by relationships between culturally different groups, based on sexuality, ethnicity, gender or race. This diversity needs to be celebrated rather than repressed: that is, the claims of groups need to be recognized and facilitated. Sandercock is not just interested in recognizing difference in procedural terms (in order to move towards a more homogenous or equal society); she is interested in "substantive difference", or affirming a society made up of different groups (Storper, 2001).

In many other ways, however, Sandercock's multiculturalism had a great deal in common with collaborative and communicative planning theories. She held with the notion of civil society as an autonomous site of resistance and social movements as primary agents of change. She placed her own work within what she terms a "radical planning model", with roots in advocacy planning, happening most often outside the formal structures of state and economy. Her work focused on agency and "the local", and on the kinds of processes and discourses which shape planning debates. As Beauregard (1998) noted, both communicative planning theorists and multicultural theory shifted the emphasis in planning theory from outcomes to process and from consequences to consciousness. Multicultural planning also retained a Habermasian concept of power in the process of communication, a position which had attracted extensive critique from Foucauldian planning theorists by the late 1990s (Flyvbjerg, 1998: Huxley \& Yiftachel, 2000).

Planning theorists have continued to write about social difference and identity, but this has not been a dominant strand in the field, and generally these ideas have not taken up Fincher and Jacob's point about the equivalent importance of place or location in constructing strategically mobilized difference. Many of these (mainstream) planning ideas make no reference to their contextual informants and assume a space-blind or universal applicability to their concepts very much along the lines of planning theories which have preceded them. Exceptions emerge from scholars who worked outside of the global North and in those parts of the world where differences are obvious (see Watson, 2012). The contributions of Caroline Moser, Carole Rakodi and Suzanne Speak to planning and gender theory are an example. Oren Yiftachel, whose writing on ethnicity, identity, land and planning is informed by the context of Israel/Palestine, has been an important voice arguing for recognition that much of mainstream planning theory, which claims universality, is in fact shaped by a global North context (Yiftachel, 2006a, 2006b). The article now turns to an emerging "framing" (Allmendinger's term) of plan- 
ning theory which questions some existing and pervasive foundational assumptions: in particular claims of universality, failure to recognize the role of context and failure to acknowledge relational historical forces which bind together and continue to shape different parts of the world.

\section{The Southern Theorizing Project in Planning}

Over the last decade or so a new set of planning ideas has emerged primarily from theorists working in, or interested in, the global South. This is a diverse set of theorists who have contributed in many different ways from different contexts. They draw on different social theories to inform their planning ideas, but in doing so they join scholars in a number of other disciplines which have taken a recent "southern turn". ${ }^{3}$ The term global South is used here, and by other southern theorists, to mean far more than a geographical South: "It references an entire history of colonialism, neo-imperialism, and differential economic and social change through which large inequalities in living standards, life expectancy and access to resources are maintained; and opens new possibilities in politics and social science" (Dados \& Connell, 2012, p. 13).

\subsection{Challenging Global North Theory}

Much planning theory to date has been produced by scholars located in the global North (Stiftel \& Mukhopadhyay, 2007), although this is beginning to shift. Much of this theorising makes some important methodological errors: this is not specific to planning theory but, it can be argued, can also be found in disciplines on which planning theory draws. Firstly, authors fail to specify the contextual informants of their research, in other words the precise nature of cities, planning systems, institutional culture, civil society etc. on which their conclusions are based. As Allmendinger (2002) showed for planning (see above) even small differences in these between the US and the UK resulted in the two rather different approaches of communicative and collaborative planning theory. Healey's (1997a, 2003, p. 117) comment that she sees her own work situated in "a particular North-west European experience" is an important recognition of this kind of influence, but there are few theorists who locate their work in this way. Newer literature is starting to recognize this problem: for example see Hytönen (2016) who uses the case of Finland to argue that sources of legitimacy in public planning might be fundamentally different outside of the Anglo-American tradition. But generally there is a failure in much current planning theory to recognize and surface the very significant differences between various parts of the world, especially between global North and South and also within these regions.

Informants of cities and planning are not only local: there are also wider and global influences of intellectual ideas and material context. Some southern planning theorists argue that planning cannot be understood outside of the reality of postcolonialism or coloniality, wherever it is studied. Social scientist Mignolo (2007, p. 476) holds that modernity and coloniality are relational and inseparably interlinked, and an understanding of modernity requires that its (ongoing) global project is taken into account: "There is no modernity without coloniality". Or as Jacobs (1996) has put it: London (for example) must be understood as a postcolonial city because of the way its colonial past shapes its present. Urban and planning theorist Ananya Roy (2009) uses the term "worlding" of cities to emphasise their linking into global circuits of various kinds, creating ever-shifting cores and peripheries, and emphasising the importance of understanding the world in an inter-connected and inter-relational way.

A second, and related, methodological error is to generalise findings from unspecified and unlocated informants to the rest of the world, in other words the incorrect universalizing of theory based on research in just one region of the world. Planning theory is not alone in doing this, in fact claiming universal relevance for global North ideas is a defining characteristic of postEnlightenment thinking and has allowed and perpetuated northern theoretical hegemony across the disciplines. In sociology, Connell (2007, p. ix) questions the "belief that social science can have only one, universal body of concepts and methods, the one created in the global North". In urban studies, a recent attempt by Scott and Storper (2014) to claim all cities can be understood through a single conceptual model of the dynamics of agglomeration and the unfolding of an associated nexus of locations, land uses and human interactions, has been roundly critiqued (see Robinson \& Roy, 2015, and others). The challenge from the latter authors is that this model is located in an understanding of (a handful of) global North cities and does not hold in most other parts of the world. The counter from Scott and Storper (2014), that city difference across the globe simply expresses empirical variation and does not warrant other theoretical models is, Robinson and Roy (2015) argue, a misreading of historical difference as empirical difference.

Dissatisfaction with global North planning theory which simply does not 'fit' outside of this context, in planning theory as well as in other disciplines, has given rise to new theorizing which in part aims to unsettle and critique northern theory and also to pave the way for new thinking about planning theory and practices.

\subsection{Southern Planning Theory?}

Planning theorists challenging the foundational "framing" of much current planning theory through writing about, from, or in relation to, planning and the material and social world outside of the global North, do not necessarily all refer to themselves as southern planning

\footnotetext{
3 In the social sciences (Comaroff \& Comaroff, 2012; Connell, 2007; Rosa, 2014); in urban studies Robinson and Roy (2015); and in gender studies Connell (2014) and Morrell (2016). See Connell (2014) for southern theory across a wide range of disciplines.
} 
theorists. Yet there are common elements that link their work: questioning the unsupported universalizing of theory from one small part of the world (the global North) to everywhere else; challenging the assumptions (often unspecified) on which these ideas are based; paying attention to global and historical forces which shape different parts of the world and the nature of the links and relationships between them; recognizing the importance of place and context and using "situated" knowledge of what happens there to speak back to theory (but not to all other places, as universalized theory tries to do); and recognizing that the extent of difference between places and people goes beyond minor empirical variation and requires new conceptual thinking.

These planning theorists have drawn on global historical processes (capitalism, imperialism, postcolonialism); local, in-depth understanding of particular cities and regions; and various forms of community resistance, to raise new ideas. A common thread which runs across many of these new ideas is the need to understand and work with the fundamental divisions and conflicts which shape societies in all parts of the world, but often more severely in global South regions. Habermasian concepts of power and consensual dialogue as a planning approach seem to be particularly inappropriate in these contexts. The idea that planning operates in contexts characterised by "conflicting rationalities" (Watson, 2003) between states and markets driven by the logic of modernization, control and profit, and poorer communities driven by the logic of survival, has been one way of framing these divisions. But the nature of these logics and conflicts varies across the global South, as more recent work in this area has shown-see below.

The case study research method is often used and influential new literature is emerging in the urban studies field on the value of comparative case research across global North and South (see Robinson, 2014). In planning, the single case method has long been useful where the aim is to document and analyse real-life planning events in order to build and test theory, noting a central methodological rule that it is not possible to generalize from one case to all other cases (Flyvbjerg, 2004). The complexity and diversity of urbanisms and urban processes which emerge from in-depth case study work on southern contexts support the contention that the very different processes and factors which produce cities defy the possibility of capture in a single universal theoretical model, as Scott and Storper (2014) suggest.

In a recent article Oren Yiftachel (2016) responds to these debates in urban and planning theory to suggest a different epistemology of learning about South(east) cities. Drawing on a deep understanding of a single cityJerusalem-he argues that cities like this can be used, not as universal models, but as a window to see the relational nature of urban forces, the rise of new categories and concepts, and the transformations which they bring about over time. In the case of Jerusalem it would be impossible to understand the city through one theoretical position or category: "powerful colonial, capitalist, religious, national, gender and military forces-and many sites of resistance-have co-shaped the city...(and)...have fluctuated in the levels of dominance over time" (p. 485). He emphasizes the multiple structural, and often conflicting, urban logics which shape cities, and the nature of their interaction in a particular (identified) place, producing and shaping 'real' urban spaces (p. 488). Understanding these logics and power relations through the planning and development of the city, as he suggests, clearly offers a very different approach to planning theory.

Yiftachel (2016) builds on his work on ethnicallymotivated spatial change in Israel/Palestine and elsewhere. His particular concern is with ethnicity 'at home' where ethno-nationalistic states use space and (ethnocratic) planning as a tool of political repression against ethnically marginalized castes, races, religions or cultures: the Palestinians in Israel or African people in apartheid South Africa, for example. In developing this line of argument, Yiftachel (2006b, 2009) argues that ethnocracy produces 'gray' spaces which only partially incorporate the ethnically marginalized and which lie between the legal and the illegal of formal planning systems. These 'informal' settlements have planning permission withheld as a deliberate tactic of political exclusion: ethnocratic states therefore use and promote informality as a way of containing the 'ungovernable'.

In a further example of using a southern case to speak back to planning and urban theory, Gautam Bhan (2016) draws on research on "basti" (informal settlement) evictions in Delhi, India, to challenge the dynamics of contemporary urbanism across 'urban peripheries' more generally. Evictions are a process which has gathered pace in Delhi and other large cities of the South, as the economic value of urban land rises and a 'middleclass' urban aesthetic takes hold. This can be described as an "elite insurgent urban citizenship that produces and claims the city" (p. 152) and which has displaced the urban poor from both urban land and the developmental imagination. While urban control takes strength from the involvement of the courts in Delhi planning processes, basti-dwellers are constantly marginalized and impoverished by these processes. This research allows Bhan to suggest new southern theorization of the "judicialization" of planning, of urban citizenship and of impoverishment and inequality.

Postcolonial theorizing (in all its diversity and recognizing colonisation as an ongoing process-as coloniality) has had a major influence on southern thinkers in planning and other disciplines. Libby Porter (2010) draws on in-depth research in Australia and other settler-colonies, to expose the ways in which Western planning ideas stereotype culture, persist in the dominance of Western norms and laws and exclude other voices of difference and dissent as a process of dispossession of indigenous populations. Ananya Roy (see 2015 and numerous earlier publications) has called for paying attention to the way in 
which the "field of action" is structured by imperial practices, and to question taken-for-granted theoretical categories such as formal/informal, global cities and so on. She calls for new ways of understanding the dynamics of urbanism and for taking into account global processes of "worlding" (the "art of being global") rather than conceptions dominated by world city and global city discourses.

Faranak Miraftab argues that a liberal notion of inclusion in planning may recognize difference and call for citizen participation but does not challenge power and merely incorporates differences (Miraftab, in press). Building on an earlier radical tradition of insurgency in planning (and James Holston's work in Latin America) she takes the idea of "insurgent planning" to colonial and postcolonial contexts and to a reliance on the direct actions of citizens to bring about change. She proposes a framework structured by the concepts of "invited" spaces of action (sanctioned and tolerated by dominant groups) and "invented" spaces of action (opened up through resistance and ostracized and criminalized by dominant groups). With similar concerns but in the different context of Southeast and Central Asia, Nihal Perera (2016) argues that subaltern classes are often unable to engage in open protest where state or corporationproduced space does not fit their needs. However, they shape urban space in more subtle and covert ways through "indigenization" of space.

The project of building new planning theory "from the South" is still in its infancy but the flurry of new ideas suggests a revival of the "hyperactivity" in planning theory which Allmendinger noted at the time of the demise of the rational scientific planning model. However, there is as yet no clarity as to what is southern planning theorizing, how it contributes to intervention (planning action), and how it will deal with the difficult issue of generalization.

\subsection{The Project of Building Planning Theory/ies "From the South"}

The newness of many of the explorations still warrants the labelling of this shift as a "southern theorizing project" in planning rather than a claim that southern planning theory has emerged. Currently such a project confronts a number of challenges. The issue of theoretical generalization raises the question: would southern planning theory not create dangerous binaries between theory for the North and theory for the South? Or is there a danger that it would repeat the parochialism of current Northern planning theory, which produces universal generalizations on the basis of contextual assumptions of planning in cities in relatively small and a-typical regions of the world? Would it not suggest that both global North and South regions and cities are relatively homogenous areas capable of categorization, when they are known to be highly diverse, continually in flux and generally resistant to categorization? These objections are justifiable: we cannot aim to replace Northern plan- ning theory with Southern planning theory, or set up artificial binaries between North and South, and certainly knowledge of cities in the global South, and the planning ideas which they might inspire, can neither be generalized to the global North, nor generalized across the very diverse territories of the global South.

Southern theorists all emphasise the importance of context and place instead of seeking to create universalized theory. But some degree of generalization is required in research if we are not to treat each city or place as entirely unique. Southern social theorist Raewyn Connell insists that a form of generalization, through the collective practice of social scientists, has "a crucial epistemological function". "Theory", she argues, "is the way we speak beyond the single case. It involves imagination, the search for patterns, the critique of data. It is how we get the criteria for comparisons and the terms of a diagnosis" (Connell, 2007, p. 225). But, she concludes, it is also about knowing the limits of such theory and where it does not apply.

This suggests some kind of meso-level of theorizing in which ideas are more or less useful in different parts of the world. But Connell cautions against "mosaic epistemologies" which involve "separate knowledge systems (that) sit beside each other like tiles in a mosaic, each based on a specific culture or historical experience, and each having its own claims to validity" (Connell, 2015, p. 59). They offer a clear alternative to universal knowledge but they tend to be fixed, subject to reification and unable to engage reflexively with other knowledge systems. On the other hand, solidarity-based epistemology allows "mutual learning on a world scale, in which different formations of knowledge are respected but enter into educational relations with each other" (Connell, 2015, p. 59). It requires, she suggests, a common orientation to social justice at the world scale framed by a postcolonial perspective. In a different approach to meso-level theorizing, Patsy Healy (2012) argues for the need to understand the "contingent universals" of any situation: in other words, understanding what is specific to a place and what can be shared learning across different localities and contexts.

A related question on southern theorizing has to do with its purpose. In anthropology the Comaroffs (2012) say their interest is in the effect of the South on theorising more generally, taking the position that southern sensitivity generates critical perspectives through being "eccentric". Contradictions can be understood better from "outside", they argue. So their interest, they say, is not in a geographical south but in "southness as eccentricity". In sociology Connell (2014) argues for uncovering and recognizing a globally operating "political economy of knowledge" which shapes and controls (through research funding, university rankings, journal publication etc.) the kind of knowledge produced in Southern regions and marginalizes its contribution to dominant theoretical production. She suggests that southern theory is not so much about making different propositions, but 
about different knowledge practices: to start learning in new ways and with new relationships.

I hold with the Nietzschean idea of perspectivism: that all ideas come from a particular perspective or position and there is no one truth or answer to planning problems that can be applicable in all contexts. The notion of perspectivism has been used as well in feminist theory (in particular the work of Donna Haraway, 1991) which challenged the belief in objectivity in science and "the view from no-where". This implies that planning research and practice needs to be firmly located in a place (or context), that the values and objectives of planning in that place are always surfaced, that concepts from other parts of the world can be tested (not simply applied) in context and new ideas (not 'best practices') can feed back to the growing and diverse international 'pot' of planning theories and concepts.

\section{Conclusion}

The field of planning theory has seen some significant shifts over the past several decades, usually influenced by theoretical shifts in other cognate disciplines and by shifts in the world's political, economic and social dynamics. While more recent planning theory has fragmented in numerous different directions and theoretical areas, a growing critique in related disciplines (especially urban studies) which questions the universalizing of Northern concepts to the rest of the world, has been paralleled by similar shifts in planning. As this article has argued, this can be seen as proposing a foundational shift as it questions the epistemological roots of much current theorizing.

While a fertile area of research appears to have opened up, one which can hopefully generate a more international body of work on planning and draw in many new voices from parts of the world previously silent, southern theorizing is still limited in terms of both contributors and scope. Particularly important, however, is that thinking needs to move beyond an understanding of contexts and into what this means for planning practice. Healey (2012) proposes transnational learning through detailed narrative case studies of planning which then carry these "origin narratives" with them if and when their relevance to other contexts is considered. As she recognizes, however, this will not overcome the deep divides and conflicts, and antagonistic norms, which characterise so many places. It is hard to escape the reality that developing planning strategies in any context is an inherently political process in which, frequently, planning ideas become attached to a political project involving domination of one group by another (and one might add, involving patronage and corruption as well). There is no shortage of issues for southern theorizers to tackle.

\section{Conflict of Interests}

The author declares no conflict of interests.

\section{References}

Allmendinger, P. (2002). Towards a post-positivist typology of planning theory. Planning Theory, 1(1), 77-99.

Beauregard, R. (1998). Writing the planner. Journal of Planning Education and Development, 18(2), 93-101.

Bhan, G. (2016). In the public's interest: Evictions, citizenship and inequality in contemporary Delhi. New Delhi: Orient Blackswan Private Limited.

Comaroff, J., \& Comaroff, J. L. (2012). Theory from the south: Or how Euro-America is evolving towards Africa. London: Paradigm Publishers.

Connell, R. (2007). Southern theory. The global dynamics of knowledge in social science. Cambridge: Polity.

Connell, R. (2014). Using southern theory: Decolonizing social thought in theory, research and application. Planning Theory, 13(2), 210-223.

Connell, R. (2015). Meeting at the edge of fear: Theory on a world scale. Feminist Theory, 16(1), 49-66.

Dados, N., \& Connell, R. (2012). The global South. Contexts, 11(1), 12-13.

Fainstein, N., \& S. S. Fainstein (2013). Restoring just outcomes to planning concerns. In N. Carmon \& S. S. Fainstein (Eds.), Policy, planning, and people: Promoting justice in urban development (pp. 32-53). Philadelphia: University of Pennsylvania Press.

Fincher, R., \& Jacobs, J. (Eds.). (1998). Cities of difference. New York and London: Guilford Press.

Flyvbjerg, B. (1998). Empowering civil society: Habermas, Foucault and the question of conflict. In M. Douglass \&J. Friedmann (Eds.), Cities for citizens (pp. 185-212). Chichester: John Wiley and Sons.

Flyvbjerg, B. (2004). Phronetic planning research: Theoretical and methodological reflections. Planning Theory and Practice, 5(3), 283-306.

Forester, J. (1989). Planning in the face of power. Berkeley: University of California Press.

Friedmann, J. (1973). Re-tracking America: A theory of transactive planning. Anchor Press: New York.

Habermas, J. (1990a). Moral consciousness and communicative action. Cambridge: MIT Press.

Habermas, J. (1990b). The theory of communicative action. Cambridge: MIT Press.

Harraway, D. (1991). Simians, cyborgs and women: The reinvention of nature. New York: Routledge.

Harris, N. (2002). Collaborative planning. In P. Allmendinger \& M. Tewdwr-Jones (Eds.) Planning futures: New directions for planning theory (pp. 21-43). London: Routledge.

Healey, P. (1992). Planning through debate: The communicative turn in planning theory. Town Planning Review, 63(2), 143-162.

Healey, P. (1997a). Situating communicative practices: Moving beyond urban political economy. Planning Theory, 17, 65-82.

Healey, P. (1997b). Collaborative planning. Shaping places in fragmented societies. London: Macmillan.

Healey, P. (1999). Institutional analysis, communicative 
planning, and shaping places. Journal of Planning Education and Research, 19(2), 111-121.

Healey, P. (2003). Collaborative planning in perspective. Planning Theory, 2(2), 101-123.

Healey, P. (2012). The universal and the contingent: Some reflections on the transnational flow of planning ideas and practices. Planning Theory, 11(2), 188-207.

Hoch, C. (1994). What planners do: Power, politics, and persuasion. Chicago: Planners Press.

Huxley, M. (2000). The limits to communicative planning. Journal of Planning Education and Research, 19(4), 369-377.

Huxley, M., \& Yiftachel, O. (2000). New paradigm or old myopia? Unsettling the communicative turn in planning theory. Journal of Planning Education and Research, 19(4), 333-342.

Hytönen, J. (2016). The problematic relationship of communicative planning theory and the Finnish legal culture. Planning Theory, 15(3), 223-238.

Innes, J. (1995). Planning theory's emerging paradigm: Communicative action and interactive practice. Journal of Planning Education and Research, 14(3), 183-189.

Jacobs, J. (1996). Edge of empire: Postcolonialism and the city. New York: Routledge.

Mignolo, W. (2007). Delinking: The rhetoric of modernity, the logic of coloniality and the grammar of decoloniality. Cultural Studies, 21(2), 449-514.

Miraftab, F. (in press). Insurgent practices and decolonization of future(s). In M. Gunder, A. Madanipour, \& V. Watson (Eds.). The Routledge handbook of planning theory. London and New York: Routledge.

Morrell, R. (2016). Making southern theory: Gender researchers in South Africa. Feminist Theory, 17(2), 191-209.

Perera, N. (2016). People's spaces. Coping, familiarizing, creating. New York and London: Routledge.

Porter, L. (2010). Unlearning the colonial cultures of planning. Aldershot: Ashgate.

Purcell, M. (2009). Resisting neoliberalization: Communicative planning or counter-hegemonic movements. Planning Theory, 8(2), 140-165.

Robinson, J. (2014). New geographies of theorising the urban: Putting comparison to work for global urban studies. In S. Parnell, \& S. Oldfield (Eds.). Handbook for cities of the global south (pp. 57-70). London: Routledge.

Robinson, J., \& Roy, A. (2015). Global urbanisms and the nature of urban theory. International Journal of Urban and Regional Research, 40(1), 181-186.
Rosa, M. (2014). Theories of the South: Limits and perspectives of an emergent movement in Social Sciences. Current Sociology, 1-17.

Roy, A. (2009). The 21st-century metropolis: New geographies of theory. Regional Studies, 43(6), 819-830.

Roy, A. (2015). Who's afraid of postcolonial theory? International Journal of Urban and Regional Research, 40(1), 200-209. doi:10.1111/1468-2427.12274

Sager, T. (1994). Communicative planning theory. Aldershot, Hants: Avebury.

Sandercock, L. (1998). Towards cosmopolis: Planning for multicultural cities. Chichester: John Wiley.

Schon, D. (1971). Beyond the stable state. London: Temple Smith.

Schon, D. (1983). The reflective practitioner. New York: Basic Books.

Scott, A. J., \& Storper, M. (2014). The nature of cities: The scope and limits of urban theory. International Journal of Urban and Regional Research, 39(1), 1-15.

Stiftel, B., \& Mukhopadhyay, C. (2007). Thoughts on Anglo-American hegemony in planning scholarship. Town Planning Review, 78(5), 545-572.

Storper, M. (2001). The poverty of radical theory today: From the false promises of Marxism to the mirage of the cultural turn. International Journal of Urban and Regional Research, 25(1), 155-179.

Watson, V. (2002). The usefulness of normative planning theories in the context of Sub-Saharan Africa. Planning Theory, 1(1), 27-52.

Watson, V. (2003). Conflicting rationalities: Implications for planning theory and ethics. Planning Theory and Practice, 4(4), 395-408.

Watson, V. (2006). Deep difference: Diversity, planning and ethics. Planning Theory, 5(1), 31-50.

Watson, V. (2012). Planning and the 'stubborn realities' of global South cities: Some emerging ideas. Planning Theory, 12(1), 81-100.

Yiftachel, O. (1989). Towards a new typology of urban planning theories. Environment and Planning B: Planning and Design, 16(1), 23-39.

Yiftachel, O. (2006a). Re-engaging planning theory? Towards 'south-eastern' perspectives. Planning Theory, 5(3), 211-222.

Yiftachel, O. (2006b). Ethnocracy: Land and identity politics in Israel/Palestine. Philadelphia: University of Pennsylvania Press.

Yiftachel, O. (2009). Critical theory and 'gray space': Mobilization of the colonized. City, 13(2-3), 246-263.

Yiftachel, O. (2016). The Aleph-Jerusalem as critical learning. City, 20(3), 483-494. doi:10.1080/1360 4813.2016.1166702 


\section{About the Author}

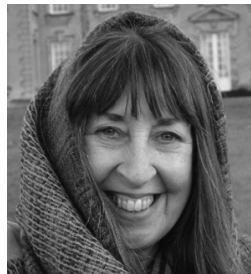

Vanessa Watson is professor of city planning in the School of Architecture, Planning and Geomatics at the University of Cape Town (South Africa). She is a Fellow of this University and is a founder and on the Board of the African Centre for Cities. She was the lead consultant for UN Habitat's 2009 Global Report on Planning Sustainable Cities and is the Global South editor for Urban Studies. 